\title{
Linking perturbations to temporal changes in diversity, stability, and compositions of neonatal calf gut microbiota: prediction of diarrhea
}

\author{
Tao Ma $\circledast^{1,2} \cdot$ Clothilde Villot $^{2,3,4} \cdot$ David Renaud $^{5} \cdot$ Andrew Skidmore $^{3,4} \cdot$ Eric Chevaux $^{3,4} \cdot$ Michael Steele $^{2,6}$. \\ Le Luo Guan ${ }^{2}$
}

Received: 29 November 2019 / Revised: 29 April 2020 / Accepted: 5 May 2020 / Published online: 22 May 2020

(c) The Author(s), under exclusive licence to International Society for Microbial Ecology 2020

\begin{abstract}
Perturbations in early life gut microbiota can have long-term impacts on host health. In this study, we investigated antimicrobial-induced temporal changes in diversity, stability, and compositions of gut microbiota in neonatal veal calves, with the objective of identifying microbial markers that predict diarrhea. A total of 220 samples from 63 calves in first 8 weeks of life were used in this study. The results suggest that increase in diversity and stability of gut microbiota over time was a feature of "healthy" (non-diarrheic) calves during early life. Therapeutic antimicrobials delayed the temporal development of diversity and taxa-function robustness (a measure of microbial stability). In addition, predicted genes associated with beta lactam and cationic antimicrobial peptide resistance were more abundant in gut microbiota of calves treated with therapeutic antimicrobials. Random forest machine learning algorithm revealed that Trueperella, Streptococcus, Dorea, uncultured Lachnospiraceae, Ruminococcus 2, and Erysipelatoclostridium may be key microbial markers that can differentiate "healthy" and "unhealthy" (diarrheic) gut microbiota, as they predicted early life diarrhea with an accuracy of $84.3 \%$. Our findings suggest that diarrhea in veal calves may be predicted by the shift in early life gut microbiota, which may provide an opportunity for early intervention (e.g., prebiotics or probiotics) to improve calf health with reduced usage of antimicrobials.
\end{abstract}

Supplementary information The online version of this article (https:// doi.org/10.1038/s41396-020-0678-3) contains supplementary material, which is available to authorized users.

$\triangle$ Le Luo Guan

lguan@ualberta.ca

1 Key Laboratory of Feed Biotechnology of the Ministry of Agriculture and Rural Affairs, Feed Research Institute, Chinese Academy of Agricultural Sciences, 100081 Beijing, China

2 Department of Agricultural, Food and Nutritional Science, University of Alberta, Edmonton, AB T6G 2P5, Canada

3 Lallemand Animal Nutrition, F-31702 Blagnac, France

4 Lallemand SAS, Milwaukee, WI 53218, USA

5 Department of Population Medicine, University of Guelph, Guelph, ON N1G 2W1, Canada

6 Department of Animal Biosciences, University of Guelph, Guelph, ON N1G 2W1, Canada

\section{Introduction}

Antimicrobials are widely used for both prevention and treatment of common infectious diseases such as diarrhea in food-producing animals during early life [1]. Young animals are particularly susceptible to infections due to their underdeveloped immune system [2] and lack of immunocompetence [3]. Increasing evidence has revealed the importance of early life gut microbiome due to its role in shaping the host immune system [4] and having a long time impact on gut health in adult life [5]. Perturbations in early life microbiome by antimicrobials have been reported to have long-term negative impacts on host immune function, including immunological defects or increased susceptibility to colonization by pathogens, in mice and human infants $[6,7]$. Despite these findings in mice and humans, the knowledge of antimicrobial-induced perturbation in gut microbiota of ruminants is scarce, especially for dairy calves. Although reduced fecal microbial diversity has been reported in calves treated with antimicrobials for respiratory disease $[8,9]$, it is not clear whether the reported reduction in microbial diversity is due to antimicrobial treatment or 
the disease itself. On the other hand, it is largely unknown how therapeutic antimicrobials affect the temporal development of microbial stability or the ability of given microbial populations to withstand direct perturbations [10] in neonatal ruminants.

The emergence of widespread antimicrobial resistance due to overuse and in some cases misuse of veterinary antimicrobials in food-producing animals has become a global health threat [11]. Some antimicrobial use is necessary to effectively treat diseases in food-producing animals, however, the prevention and control of diseases before an outbreak is more cost-effective [12]. Thus, predicting disease onset based on the gut microbiota composition [13] could provide an opportunity for early intervention with an aim to reduce the use of antimicrobials. Recent findings based on human gut or oral microbiota have enabled the tentative prediction of type-2-diabetes [14], adiposity [15], and tooth decay [16]. Therefore, we speculated that early life gut microbiota in ruminants can predict gut health status as well as onset of early life diarrhea, one of the major health threats to ruminants.

Here, we used the veal calf as an animal model to represent young ruminants. We hypothesized that either diarrhea or the use of therapeutic antimicrobials to treat diarrhea may affect temporal changes in diversity, stability, as well as taxa-function relationship of gut microbiota. In addition, we speculated that the variation in early life microbiota between healthy and diarrheic calves can be exploited to develop predictive markers for diarrhea using a random forest machine learning algorithm.

\section{Materials and methods}

\section{Assessment of calf health status and sample collection}

Holstein male veal calves sourced from local Ontario (Canada) farms and free from antimicrobials prior to their arrival were enrolled in this study. Upon arrival, all animals were transferred to the experimental farm and individually examined to ensure they were all free of disease, injury, and dehydration. The health condition of each calf was evaluated daily over the 56-day experiment period. The animal experiment was conducted following the instructions of the Canadian Council of Animal Care and the experiment protocol was approved by the Livestock Care Committee of the University of Alberta (AUP00001595). The general appearance, fecal score, rectal temperature, umbilical score, and respiratory score were recorded as reported by Villot et al. [17]. Briefly, a total of 84 calves were enrolled with 42 fed milk replacer $(\mathrm{CON})$ and the other 42 fed milk replacer with Saccharomyces cerevisiae boulardii (SCB). The milk replacer contained $63 \%$ of skim milk powder with $260 \mathrm{~g} / \mathrm{kg}$ crude protein, $160 \mathrm{~g} / \mathrm{kg}$ crude fat, and $19.2 \mathrm{MJ} / \mathrm{kg}$ metabolizable energy on a dry matter basis (Grober Animal Nutrition, Cambridge, ON, Canada). Calves with diarrhea (defined as when the fecal score was $\geq 2$, meaning a fecal sample is either loose but stays on top of mat, or watery and sifts through the mat, for at least 2 days [18]) received 21 of oral electrolytes (Calf Lyte II, Vetoquinol, Lavaltrie, QC, Canada) once daily over the entire experimental period. If no improvement was observed after electrolyte treatment or if severe diarrhea (dehydration and attitude scores $>0$ and fecal score $\geq 2$ ) was detected, calves were treated with trimethoprim sulfa (Trimidox, $0.7 \mathrm{ml} / 10 \mathrm{~kg} \mathrm{BW}$, Vetoquinol) for 3 consecutive days. If a calf was still diarrheic after treatment, it was treated with Excenel $(0.2 \mathrm{ml} / 10 \mathrm{~kg} \mathrm{BW}$, Zoetis, Kirkland, QC, Canada) for another 3 consecutive days. Fecal samples $(\sim 20 \mathrm{~g})$ were collected directly from the rectum by rectal palpation at 7 (on arrival), then again at 14 , 21,42 , and 56 days of age, and were stored at $-20^{\circ} \mathrm{C}$ immediately after collection.

\section{Classification of health status of calves}

Calves that never exhibited diarrhea were classified as "healthy to healthy" $(\mathrm{H} 2 \mathrm{H})$, those that exhibited diarrhea and recovered after treated with electrolyte, indicating that their gut microbiota may be more resistant to diarrheainduced dysbiosis so that no antimicrobials were needed, were classified as "resistant to healthy" $(\mathrm{R} 2 \mathrm{H})$, and those that exhibited diarrhea and recovered after treated with Trimidox or Excenel, indicating that their gut microbiota may be more susceptible to diarrhea-induced dysbiosis so that antimicrobials were needed, were classified as "susceptible to healthy" (S2H) (Table 1). In other words, calves were classified into three groups depending on the potential perturbations that their fecal microbiota experienced: $\mathrm{H} 2 \mathrm{H}$, no perturbations; $\mathrm{R} 2 \mathrm{H}$, diarrhea as the perturbation; $\mathrm{S} 2 \mathrm{H}$, therapeutic antimicrobials as the perturbation.

In this study, we did not include any individual calf supplemented with SCB in $\mathrm{H} 2 \mathrm{H}$ group. This is because at 7 days of age no Saccharomyces boulardii was supplemented to calves in SCB group. Considering that supplementing SCB effectively decreased the incidence of diarrhea (SCB, 50.0\%, 21/42 vs. CON, 69.1\%, 29/42) [17], we were not sure if healthy calves in SCB group could still be healthy if SCB had not been supplemented. Therefore, only 21 calves exhibiting diarrhea in SCB group were enrolled in the current study, as SCB is a nonpathogenic biotherapeutic agent [19] and it should not contribute to the incidence of diarrhea with the dosage supplemented. Seven calves died during the experiment (Table 1) and the remaining 56 calves were healthy at 56 days of age. 
Table 1 Grouping information of veal calves used in the current study.

\begin{tabular}{|c|c|c|c|c|c|c|c|c|}
\hline \multirow[t]{2}{*}{ Calf ID } & \multirow[t]{2}{*}{ Group } & \multirow{2}{*}{$\begin{array}{l}\text { Age of mortality } \\
\text { (day) }\end{array}$} & \multirow{2}{*}{$\begin{array}{l}\text { Age of first diarrhea } \\
\text { case (day) }\end{array}$} & \multicolumn{5}{|c|}{ Age of sample collection (day) } \\
\hline & & & & 7 & 14 & 21 & 42 & 56 \\
\hline 3 & $\mathrm{CON}-\mathrm{H} 2 \mathrm{H}$ & - & - & $\mathrm{T}+\mathrm{RF}(\mathrm{H})$ & $\mathrm{T}+\mathrm{RF}(\mathrm{H})$ & $\mathrm{T}+\mathrm{RF}(\mathrm{H})$ & $\mathrm{T}$ & $\mathrm{T}$ \\
\hline 5 & $(n=13)$ & - & - & $\mathrm{T}+\mathrm{RF}(\mathrm{H})$ & $\mathrm{T}+\mathrm{RF}(\mathrm{H})$ & $\mathrm{T}+\mathrm{RF}(\mathrm{H})$ & $\mathrm{T}$ & $\mathrm{T}$ \\
\hline 26 & & - & - & $\mathrm{T}+\mathrm{RF}(\mathrm{H})$ & $\mathrm{T}+\mathrm{RF}(\mathrm{H})$ & $\mathrm{T}+\mathrm{RF}(\mathrm{H})$ & $\mathrm{T}$ & $\mathrm{T}$ \\
\hline 36 & & - & - & $\mathrm{T}+\mathrm{RF}(\mathrm{H})$ & $\mathrm{T}+\mathrm{RF}(\mathrm{H})$ & $\mathrm{T}+\mathrm{RF}(\mathrm{H})$ & $\mathrm{T}$ & $\mathrm{T}$ \\
\hline 37 & & - & - & $\mathrm{T}+\mathrm{RF}(\mathrm{H})$ & $\mathrm{T}+\mathrm{RF}(\mathrm{H})$ & $\mathrm{T}+\mathrm{RF}(\mathrm{H})$ & $\mathrm{T}$ & $\mathrm{T}$ \\
\hline 43 & & - & - & $\mathrm{T}+\mathrm{RF}(\mathrm{H})$ & $\mathrm{T}+\mathrm{RF}(\mathrm{H})$ & $\mathrm{T}+\mathrm{RF}(\mathrm{H})$ & $\mathrm{T}$ & $\mathrm{T}$ \\
\hline 44 & & - & - & $\mathrm{T}+\mathrm{RF}(\mathrm{H})$ & $\mathrm{T}+\mathrm{RF}(\mathrm{H})$ & $\mathrm{T}+\mathrm{RF}(\mathrm{H})$ & $\mathrm{T}$ & $\mathrm{T}$ \\
\hline 47 & & - & - & $\mathrm{T}+\mathrm{RF}(\mathrm{H})$ & $\mathrm{T}+\mathrm{RF}(\mathrm{H})$ & $\mathrm{T}+\mathrm{RF}(\mathrm{H})$ & $\mathrm{T}$ & $\mathrm{T}$ \\
\hline 54 & & - & - & $\mathrm{T}+\mathrm{RF}(\mathrm{H})$ & $\mathrm{T}+\mathrm{RF}(\mathrm{H})$ & $\mathrm{T}+\mathrm{RF}(\mathrm{H})$ & $\mathrm{T}$ & $\mathrm{T}$ \\
\hline 69 & & - & - & $\mathrm{T}+\mathrm{RF}(\mathrm{H})$ & $\mathrm{T}+\mathrm{RF}(\mathrm{H})$ & $\mathrm{T}+\mathrm{RF}(\mathrm{H})$ & $\mathrm{T}$ & $\mathrm{T}$ \\
\hline 52 & & - & - & $\mathrm{T}+\mathrm{RF}(\mathrm{H})$ & $\mathrm{T}+\mathrm{RF}(\mathrm{H})$ & $\mathrm{T}+\mathrm{RF}(\mathrm{H})$ & $\mathrm{T}$ & $\mathrm{T}$ \\
\hline 71 & & - & - & $\mathrm{T}+\mathrm{RF}(\mathrm{H})$ & $\mathrm{T}+\mathrm{RF}(\mathrm{H})$ & $\mathrm{T}+\mathrm{RF}(\mathrm{H})$ & $\mathrm{T}$ & $\mathrm{T}$ \\
\hline 76 & & - & - & $\mathrm{T}+\mathrm{RF}(\mathrm{H})$ & $\mathrm{T}+\mathrm{RF}(\mathrm{H})$ & $\mathrm{T}+\mathrm{RF}(\mathrm{H})$ & $\mathrm{T}$ & $\mathrm{T}$ \\
\hline 1 & $\mathrm{CON}-\mathrm{R} 2 \mathrm{H}$ & - & 14 & $\mathrm{~T}+\mathrm{RF}(\mathrm{U})$ & $\mathrm{T}$ & $\mathrm{T}$ & $\mathrm{T}$ & $\mathrm{T}$ \\
\hline 2 & $(n=18)$ & - & 12 & $\mathrm{~T}+\mathrm{RF}(\mathrm{U})$ & $\mathrm{T}$ & $\mathrm{T}$ & $\mathrm{T}$ & $\mathrm{T}$ \\
\hline 10 & & - & 8 & $\mathrm{~T}+\mathrm{RF}(\mathrm{U})$ & $\mathrm{T}$ & $\mathrm{T}$ & $\mathrm{T}$ & $\mathrm{T}$ \\
\hline 13 & & 24 & 11 & $\mathrm{~T}+\mathrm{RF}(\mathrm{U})$ & $\mathrm{T}$ & $\mathrm{T}$ & & \\
\hline 18 & & - & 10 & $\mathrm{~T}+\mathrm{RF}(\mathrm{U})$ & $\mathrm{T}$ & $\mathrm{T}$ & $\mathrm{T}$ & $\mathrm{T}$ \\
\hline 20 & & 24 & 26 & $\mathrm{~T}+\mathrm{RF}(\mathrm{U})$ & $\mathrm{T}+\mathrm{RF}(\mathrm{U})$ & $\mathrm{T}+\mathrm{RF}(\mathrm{U})$ & & \\
\hline 21 & & - & 8 & $\mathrm{~T}+\mathrm{RF}(\mathrm{U})$ & $\mathrm{T}$ & $\mathrm{T}$ & $\mathrm{T}$ & $\mathrm{T}$ \\
\hline 27 & & - & 14 & $\mathrm{~T}+\mathrm{RF}(\mathrm{U})$ & $\mathrm{T}$ & $\mathrm{T}$ & $\mathrm{T}$ & $\mathrm{T}$ \\
\hline 29 & & - & 12 & $\mathrm{~T}+\mathrm{RF}(\mathrm{U})$ & $\mathrm{T}$ & $\mathrm{T}$ & $\mathrm{T}$ & $\mathrm{T}$ \\
\hline 34 & & - & 12 & $\mathrm{~T}+\mathrm{RF}(\mathrm{U})$ & $\mathrm{T}$ & $\mathrm{T}$ & $\mathrm{T}$ & $\mathrm{T}$ \\
\hline 35 & & - & 18 & $\mathrm{~T}+\mathrm{RF}(\mathrm{U})$ & $\mathrm{T}+\mathrm{RF}(\mathrm{U})$ & $\mathrm{T}$ & $\mathrm{T}$ & $\mathrm{T}$ \\
\hline 46 & & - & 9 & $\mathrm{~T}+\mathrm{RF}(\mathrm{U})$ & $\mathrm{T}$ & $\mathrm{T}$ & $\mathrm{T}$ & $\mathrm{T}$ \\
\hline 55 & & - & 11 & $\mathrm{~T}+\mathrm{RF}(\mathrm{U})$ & $\mathrm{T}$ & $\mathrm{T}$ & $\mathrm{T}$ & $\mathrm{T}$ \\
\hline 60 & & - & 12 & $\mathrm{~T}+\mathrm{RF}(\mathrm{U})$ & $\mathrm{T}$ & $\mathrm{T}$ & $\mathrm{T}$ & $\mathrm{T}$ \\
\hline 68 & & - & 12 & $\mathrm{~T}+\mathrm{RF}(\mathrm{U})$ & $\mathrm{T}$ & $\mathrm{T}$ & $\mathrm{T}$ & $\mathrm{T}$ \\
\hline 70 & & - & 13 & $\mathrm{~T}+\mathrm{RF}(\mathrm{U})$ & $\mathrm{T}$ & $\mathrm{T}$ & $\mathrm{T}$ & $\mathrm{T}$ \\
\hline 77 & & - & 8 & $\mathrm{~T}+\mathrm{RF}(\mathrm{U})$ & $\mathrm{T}$ & $\mathrm{T}$ & $\mathrm{T}$ & $\mathrm{T}$ \\
\hline 78 & & - & 11 & $\mathrm{~T}+\mathrm{RF}(\mathrm{U})$ & $\mathrm{T}$ & $\mathrm{T}$ & $\mathrm{T}$ & $\mathrm{T}$ \\
\hline 4 & $\mathrm{CON}-\mathrm{S} 2 \mathrm{H}$ & 7 & 10 & $\mathrm{RF}(\mathrm{U})$ & & & & \\
\hline 11 & $(n=11)$ & 15 & 12 & $\mathrm{RF}(\mathrm{U})$ & & & & \\
\hline 12 & & - & 8 & $\mathrm{~T}+\mathrm{RF}(\mathrm{U})$ & $\mathrm{T}$ & $\mathrm{T}$ & $\mathrm{T}$ & $\mathrm{T}$ \\
\hline 19 & & 12 & 8 & $\mathrm{RF}(\mathrm{U})$ & & & & \\
\hline 28 & & - & 13 & $\mathrm{~T}+\mathrm{RF}(\mathrm{U})$ & $\mathrm{T}$ & $\mathrm{T}$ & $\mathrm{T}$ & $\mathrm{T}$ \\
\hline 45 & & - & 11 & $\mathrm{~T}+\mathrm{RF}(\mathrm{U})$ & $\mathrm{T}$ & $\mathrm{T}$ & $\mathrm{T}$ & $\mathrm{T}$ \\
\hline 53 & & - & 12 & $\mathrm{RF}(\mathrm{U})$ & $\mathrm{T}$ & $\mathrm{T}$ & $\mathrm{T}$ & $\mathrm{T}$ \\
\hline 61 & & - & 15 & $\mathrm{~T}+\mathrm{RF}(\mathrm{U})$ & $\mathrm{T}+\mathrm{RF}(\mathrm{U})$ & $\mathrm{T}$ & $\mathrm{T}$ & $\mathrm{T}$ \\
\hline 62 & & - & 13 & $\mathrm{~T}+\mathrm{RF}(\mathrm{U})$ & $\mathrm{T}$ & $\mathrm{T}$ & $\mathrm{T}$ & $\mathrm{T}$ \\
\hline 63 & & - & 11 & $\mathrm{~T}+\mathrm{RF}(\mathrm{U})$ & $\mathrm{T}$ & $\mathrm{T}$ & $\mathrm{T}$ & $\mathrm{T}$ \\
\hline 79 & & - & 19 & $\mathrm{~T}+\mathrm{RF}(\mathrm{U})$ & $\mathrm{T}$ & $\mathrm{T}$ & $\mathrm{T}$ & $\mathrm{T}$ \\
\hline 6 & $\mathrm{SCB}-\mathrm{R} 2 \mathrm{H}$ & - & 12 & $\mathrm{RF}(\mathrm{U})$ & & & & \\
\hline 15 & $(n=15)$ & - & 12 & $\mathrm{RF}(\mathrm{U})$ & & & & \\
\hline 16 & & - & 8 & $\mathrm{RF}(\mathrm{U})$ & & & & \\
\hline 17 & & - & 12 & RF (U) & & & & \\
\hline
\end{tabular}


Table 1 (continued)

\begin{tabular}{|c|c|c|c|c|c|c|c|}
\hline \multirow[t]{2}{*}{ Calf ID } & \multirow[t]{2}{*}{ Group } & \multirow{2}{*}{$\begin{array}{l}\text { Age of mortality } \\
\text { (day) }\end{array}$} & \multirow{2}{*}{$\begin{array}{l}\text { Age of first diarrhea } \\
\text { case (day) }\end{array}$} & \multicolumn{4}{|c|}{ Age of sample collection (day) } \\
\hline & & & & 7 & 14 & 21 & $42 \quad 56$ \\
\hline 22 & & - & 9 & $\mathrm{RF}(\mathrm{U})$ & & & \\
\hline 25 & & - & 10 & $\mathrm{RF}(\mathrm{U})$ & & & \\
\hline 38 & & - & 11 & $\mathrm{RF}(\mathrm{U})$ & & & \\
\hline 49 & & - & 12 & $\mathrm{RF}(\mathrm{U})$ & & & \\
\hline 50 & & - & 11 & $\mathrm{RF}(\mathrm{U})$ & & & \\
\hline 66 & & - & 8 & $\mathrm{RF}(\mathrm{U})$ & & & \\
\hline 72 & & - & 12 & $\mathrm{RF}(\mathrm{U})$ & & & \\
\hline 73 & & - & 8 & $\mathrm{RF}(\mathrm{U})$ & & & \\
\hline 81 & & - & 12 & $\mathrm{RF}(\mathrm{U})$ & & & \\
\hline 82 & & - & 12 & $\mathrm{RF}(\mathrm{U})$ & & & \\
\hline 83 & & - & 11 & $\mathrm{RF}(\mathrm{U})$ & & & \\
\hline 7 & $\mathrm{SCB}-\mathrm{S} 2 \mathrm{H}$ & - & 32 & $\mathrm{RF}(\mathrm{U})$ & RF (U) & RF (U) & \\
\hline 24 & $(n=6)$ & 27 & 13 & $\mathrm{RF}(\mathrm{U})$ & & & \\
\hline 40 & & - & 12 & $\mathrm{RF}(\mathrm{U})$ & & & \\
\hline 41 & & - & 12 & $\mathrm{RF}(\mathrm{U})$ & & & \\
\hline 42 & & 22 & 19 & $\mathrm{RF}(\mathrm{U})$ & RF (U) & & \\
\hline 57 & & _- & 32 & $\mathrm{RF}(\mathrm{U})$ & $\mathrm{RF}(\mathrm{U})$ & $\mathrm{RF}(\mathrm{U})$ & \\
\hline
\end{tabular}

CON: calves fed milk replacer only; SCB: calves fed milk replacer and supplemented with $5 \mathrm{~g}$ of live Saccharomyces cerevisiae boulardii per day; T: samples used for analysis of temporal changes in microbial diversity, stability, composition, and taxa-function robustness; RF: samples used for random forest machine learning algorithm. $(\mathrm{H})$ and $(\mathrm{U})$ mean 'healthy' and 'unhealthy' microbiota, respectively; $\mathrm{T}+\mathrm{RF}$ : samples used for both analysis of temporal changes in microbial diversity, stability, composition, and taxa-function robustness, and random forest machine learning algorithm.

$H 2 H$ healthy to healthy: calves never exhibited diarrhea, $R 2 H$ resistant to healthy: calves exhibited diarrhea but not treated with Trimidox or Excenel, $S 2 H$ susceptible to healthy: calves exhibited diarrhea and treated with Trimidox or Excenel.

\section{DNA extraction, PCR amplification, and sequencing}

Total DNA was extracted from fecal samples (standardized by DM concentration) using the repeated bead beating plus column method [20]. Briefly, $0.2 \pm 0.1 \mathrm{~g}$ of sample was washed twice with TE buffer following with supplementation with cell lysis buffer containing $20 \%$ SDS, and physical disruption at $5000 \mathrm{rpm}$ for 3 min using Biospec Mini Beads Beater 8 (BioSpec, Bartlesville, OK), incubation at $70{ }^{\circ} \mathrm{C}$ for $15 \mathrm{~min}$ and centrifugation at $16,000 \times g$ for $5 \mathrm{~min}$. The bead-beating, incubation, and centrifugation procedures were repeated, and impurities were removed from the supernatant using $10 \mathrm{M}$ ammonium acetate, followed by DNA precipitation using isopropanol. After precipitation, DNA was purified with QIAmp fast DNA stool mini kit (Qiagen Inc, Germantown, MD). DNA quantity and purity were checked using NanoDrop 1000 spectrophotometer (Nanodrop Technologies, Wilmington, DE).

Amplification of V1-V3 hypervariable regions of the 16S rRNA gene for amplicon sequencing was conducted with $27 \mathrm{~F}$ and 515R primers (27F-CS1F: ACACTGACGACATGGTT CTACAGAGTTTGATCMTGGCTCAG, 515R-CS2R: TAC GGTAGCAGAGACTTGGTCTCCGCGGCKGCTGGCAC)
[21]. The amplicon DNA with targeted size ( $\sim 500 \mathrm{bp})$ was purified from $1 \%$ agarose gel using QIAEX II gel extraction kit (Qiagen Science, MD). The quality and quantity of purified PCR products were checked using a NanoDrop 1000 (NanoDrop Technologies, Wilmington, DE) to ensure that the concentration of DNA of all samples was above $25 \mathrm{ng} / \mu \mathrm{l}$. In addition, negative controls without sample DNA were also sequenced. The amplicons were sequenced at Genome Quebec at McGill University (Montreal, QC, Canada) using Illumina's MiSeq platform $(2 \times 300$, pair end $)$.

\section{Analysis of taxonomic and functional composition}

Sequencing data were processed using QIIME2 (version 2019.7; ref. [22]). Paired sequences were demultiplexed with "demux" plugin and subjected to quality control using "dada2" plugin [23]. To eliminate potential sequence contaminants, three amplicon sequence variants (ASVs) (two were identified as $E$. coli strains and the third was identified as an uncultured bacterium) identified in negative controls were removed from all samples. Then, 60 ASVs inversely correlated with DNA concentration were further removed using the "decontam" package in R [24]. Finally, taxonomy 
was assigned to filtered ASVs using a pretrained QIIME2compatible SILVA 132 database with $99 \%$ identity for bacteria and assigned taxonomies to representative sequences. The number of shared bacterial genera was visualized using a Venn diagram [25]. To investigate how shifts in microbial composition impact the functional composition, microbial functionality (protein coding genes) at each day of age was predicted using the "q2-picrust2" plugin in QIIME2 [26].

\section{Assessment of temporal changes in microbial diversity and stability}

The temporal changes in microbial diversity and stability were evaluated using fecal microbiota from the three groups of CON calves only. Fecal microbiota SCB group was excluded due to the concern of potential interaction between SCB and diarrhea/therapeutic antimicrobials. Shannon index and Bray-Curtis distance matrix were computed with a sample depth of 2714 using the "diversity" plugin in QIIME2. Bray-Curtis distance between two successive samples was further computed using the "q2-longitudinal" plugin in QIIME2 [27]. The coefficient of variation (CV) was calculated for Shannon indices for each individual over time with lower $\mathrm{CV}$ values indicating relatively stable alpha diversity among individuals and vice versa.

Taxa-function robustness was used to assess microbial stability, which defines the degree to which a shift/perturbation in a community's taxonomic composition will impact its functional capacities [28]. To quantitatively compare taxa-function robustness between communities, varying perturbations of each community's taxonomic composition was simulated and the average shift in the functional profile of a community as a power function of the taxonomic perturbation magnitude (taxa-function response curve; Fig. S1a) was established as follows:

$f=\frac{1}{e^{a}} t^{b}$

where $t$ indicates the magnitude of simulated taxonomic perturbation, $f$ indicates the expected shift in functional capacity. Two coefficients in the function, $a$ (attenuation) and $b$ (buffering), were used to directly evaluate taxa-function robustness. Attenuation is defined as inversely proportional to the response curve slope, indicating the expected rate at which increases in the taxonomic perturbation magnitude are expected to increase functional profile shifts [28]. Buffering indicates how large a perturbation must be before a functional profile shift becomes noticeable and approaches the expected shift magnitude defined by attenuation (Fig. S1b) [28]. Therefore, the higher the attenuation and buffering values, the more stable the functional capacity of a community.

\section{Predictive modeling of early life diarrhea and validation of markers}

One major aim of the current study was to investigate if early life microbiota could be applied to predict diarrhea in neonatal calves, the incidence of which occurred mostly between 7 and 21 days of age [29]. Therefore, the microbiota collected from $\mathrm{H} 2 \mathrm{H}$ calves at 7, 14, and 21 days of age were defined as "healthy" ( $n=39$ from $\mathrm{CON})$, while those collected from $\mathrm{R} 2 \mathrm{H}$ and $\mathrm{S} 2 \mathrm{H}$ calves prior to the onset of diarrhea in both CON $(n=33)$ and SCB groups $(n=26)$ were defined as "unhealthy" (Table 1).

To establish the model for predicting diarrhea, random forest algorithms ("randomForest" package in R) were used to identify "healthy" and "unhealthy" microbiota based on the relative abundance of selected bacterial genera. The accuracy of selected bacterial genera was then assessed by area under the receiver-operating characteristic (AUC) ("roc.curve" package) in R. To further minimize the potential over-fitting in the model, a threefold crossvalidation approach ("trainControl" package in $\mathrm{R}$ ) was applied [30]. The threefold cross-validation method splits 98 samples into three disjoint (nonoverlapping) subsets with similar number of samples (e.g. 33, 33, and 32). Then, two subsets (containing 66/65 samples) were used to train the model and the other subset (containing 32/33 samples, totally different from two subsets for training) was used to test the results. The threefold cross-validation was completed until accuracy was determined for each permutation and combination of samples in the subsets, and then an overall accuracy was estimated. The AUC of the optimized model was calculated using "roc.curve" package in R.

The difference in relative abundance of certain taxa between two conditions may not necessarily reflect the difference in their true abundance due to the lack of total microbial load [31]. We further performed differential abundance analysis to identify and rank the microbial markers that were truly different between "healthy" and "unhealthy" microbiota using multinomial regression as implemented in TensorFlow [32]. Such analysis ranks the microbes that are changing the most relative to each other between two conditions, and the ranks of relative differentials are identical to the ranks of absolute differentials in abundance [33].

\section{Statistical analyses}

Temporal changes in Shannon index, Bray-Curtis distance between 2 successive days of age, attenuation, and buffering values within each group were assessed using the nonparametric Friedman test with calves as repeated measures, and multiple comparison was conducted using Wilcoxon signed-rank test. Differences in CV of Shannon 

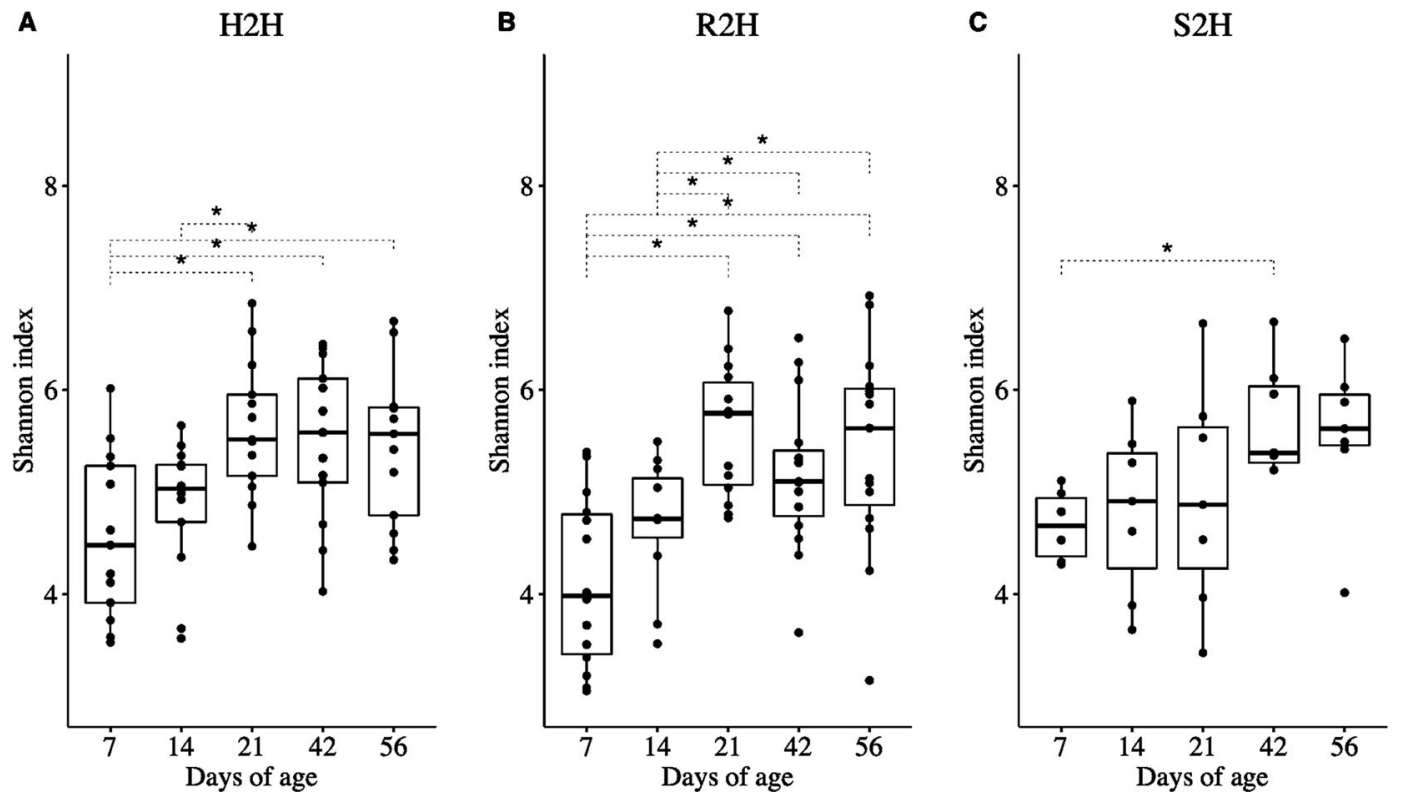

Fig. 1 Temporal changes of Shannon index in gut microbiota. a Calves that never exhibited diarrhea $(\mathrm{H} 2 \mathrm{H})$. b Calves that exhibited diarrhea but not treated with Trimidox or Excenel (R2H). c Calves that exhibited diarrhea and treated with Trimidox or Excenel $(\mathrm{S} 2 \mathrm{H})$.

index, the relative abundance of fecal bacterial genera, and predicted genes at each days of age among three groups of calves, were assessed using the nonparametric Kruskal-Wallis test, and multiple comparison was conducted based on Mann-Whitney $U$ test. The $P$ value of multiple comparison of each test was adjusted into false discovery rate using the Benjamini-Hochbert $(\mathrm{BH})$ algorithm [34]. Significant difference was declared at $P \leq 0.05$ and tendencies at $0.05<P \leq 0.10$.

\section{Nucleotide sequence accession numbers}

All DNA sequences were deposited in the NCBI sequence read archive and are accessible under the project number PRJNA506828.

\section{Results}

\section{Temporal changes in microbial diversity and stability of gut microbiota within each group}

For gut microbiota in $\mathrm{H} 2 \mathrm{H}$ calves, Shannon index was higher at $21(P=0.029), 42(P=0.029)$, and $56(P=$ $0.030)$ than 7 days of age and was higher at $21(P=0.029)$ than 14 days of age (Fig. 1a). For R2H calves, Shannon index was higher at $21(P=0.002), 42(P=0.005)$, and 56 $(P=0.002)$ than at both 7 and 14 days of age (Fig. 1b). For S2H calves, Shannon index was higher at $42(P=0.006)$
Statistical analysis was done by Friedman test and multiple comparisons were performed based on Wilcoxon signed-rank test and subjected to "BH" $P$ value adjustment $(* P \leq 0.05)$.

than 7 days of age (Fig. 1c). The CV of Shannon index in R2H calves was higher than that in $\mathrm{S} 2 \mathrm{H}(P=0.024)$ calves (Fig. S2).

The temporal changes in microbial variability were then investigated by assessing beta diversity (Bray-Curtis distance) between two successive days of age from the same calf changed over time among three groups of CON calves. Bray-Curtis distance between 42 vs. 21 days of age was significantly lower than that between 14 vs. 7 days of age in $\mathrm{H} 2 \mathrm{H}(P=0.014)$ (Fig. 2a) and R2H $(P<0.001)$ (Fig. 2b) calves. On the other hand, the Bray-Curtis distance between 56 vs. 42 days of age was significantly lower than that between 14 vs. 7 age in S2H calves $(P=0.014)$ (Fig. 2c).

Furthermore, temporal stability of microbiota was evaluated by attenuation and buffering values. The attenuation value of gut microbiota was higher at $21(P<0.001)$ and 42 $(P<0.001)$ than 7 days of age in $\mathrm{H} 2 \mathrm{H}$ calves, at 42 than 7 days of age $(P=0.025)$ in $\mathrm{R} 2 \mathrm{H}$ calves, and was not different among all age groups in $\mathrm{S} 2 \mathrm{H}$ calves $(P=0.179)$ (Fig. 3a-c). The buffering value was not different among age in either $\mathrm{H} 2 \mathrm{H}(P=0.077), \mathrm{R} 2 \mathrm{H}(P=0.371)$, or S2H $(P=0.195)$ calves (Fig. 3d-f).

\section{Comparison of temporal changes in taxonomic composition and predicted genes of gut microbiota}

A total of $11,498,965$ high-quality reads were generated from 220 fecal samples for the 63 calves. After quality control and removal of potential contaminants, the 
A

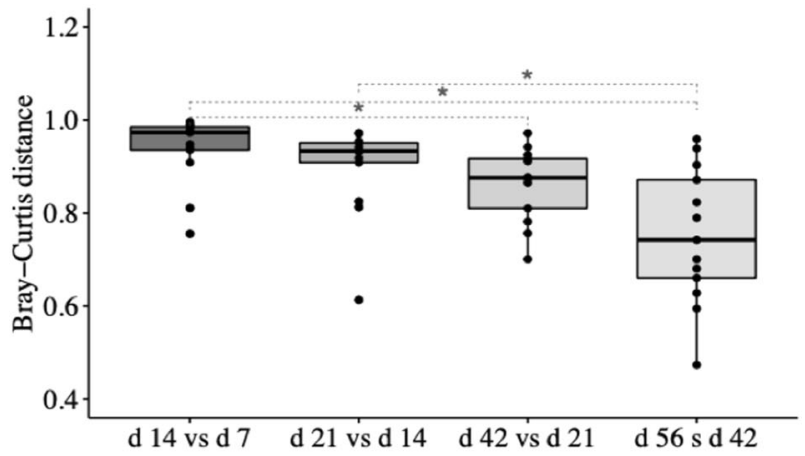

B

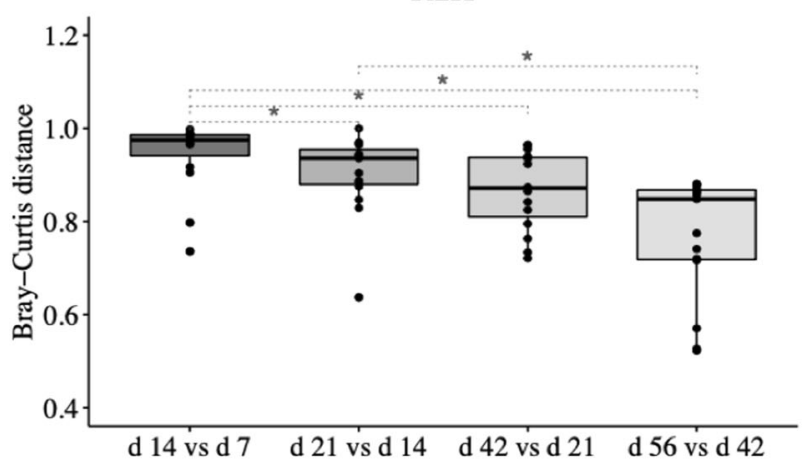

C

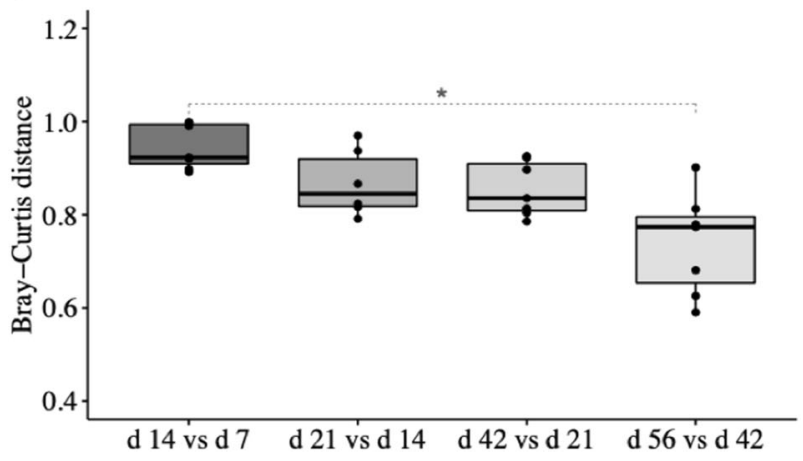

Fig. 2 Temporal changes of Bray-Curtis distance between two successive days of age at sampling in gut microbiota. a Calves that never exhibited diarrhea $(\mathrm{H} 2 \mathrm{H})$; b calves that exhibited diarrhea but not treated with Trimidox or Excenel $(\mathrm{R} 2 \mathrm{H})$; c calves that exhibited diarrhea and treated with Trimidox or Excenel $(\mathrm{S} 2 \mathrm{H})$. Statistical analysis was done by Friedman test and multiple comparisons were performed based on Wilcoxon signed-rank test and subjected to "BH" $P$ value adjustment $(* P \leq 0.05)$.

remaining 3,529,111 reads were assigned to 8331 ASVs, with an average of $16,568 \pm 448$ (average \pm standard error) reads and $140 \pm 4$ ASVs per sample based on a $99 \%$ nucleotide sequence similarity. At each age, a total of 22, $30,34,31$, and 31 bacterial genera were identified (defined as the taxon with the relative abundance $>0.1 \%$ and present in more than half of the samples within each age group) in $\mathrm{H} 2 \mathrm{H}$ calves (Fig. S3a), 22, 23, 38, 28, and 42 bacterial genera were identified in $\mathrm{R} 2 \mathrm{H}$ calves (Fig. S3b), while 25, $28,33,35$, and 39 bacterial genera were identified in $\mathrm{S} 2 \mathrm{H}$ calves (Fig. S3c), at 7, 14, 21, 42, and 56 days of age, respectively.

A total of 17, 20,21, 19, and 28 bacterial genera were shared among three groups of calves at 7, 14, 21, 42, and 56 days of age, respectively (Table S1). At 14 days of age, the relative abundance of Blautia $(P=0.058$; Fig. S4a) tended to be higher, while that of Escherichia-Shigella $(P$ $=0.067$; Fig. S4b) tended to be lower in $\mathrm{H} 2 \mathrm{H}$ than $\mathrm{R} 2 \mathrm{H}$ calves. At 42 days of age, the relative abundance of unclassified Ruminococcaceae was higher in $\mathrm{H} 2 \mathrm{H}$ than that in $\mathrm{R} 2 \mathrm{H}$ calves $(P=0.021$; Fig. S4c). No difference was observed in the relative abundance of any bacterial genus shared among the three groups of veal calves at 7,21 , or 56 days of age.

Based on the results of PICRUSt2, the relative abundance of three predicted protein coding genes associated with beta-lactam resistance, including "bla regulator protein blaRl" (K02172), "penicillin-binding protein 1" (K12552), and "penicillin-binding protein 3" (K12553), as well as one predicted gene associated with cationic antimicrobial peptide resistance, "aureolysin" (K01401), was significantly different among calves at 56 days of age. Specifically, the relative abundance of $\mathrm{K} 02172(P=0.007$ and 0.034 ; Fig. S5a), K12552 $(P=0.012$ and 0.036; Fig. S5b), $\mathrm{K} 12553(P=0.014$ and 0.035 ; Fig. S5c), and K01401 $(P=$ 0.012 and 0.035 ; Fig. S5d) was higher in $\mathrm{S} 2 \mathrm{H}$ than both $\mathrm{H} 2 \mathrm{H}$ and $\mathrm{R} 2 \mathrm{H}$ calves, respectively.

\section{Prediction of disease onset based on bacterial markers in early gut microbiota}

The random forest supervised machine learning algorithm was applied to construct the model for predicting early life diarrhea in veal calves. Fifty-two bacterial genera were excluded prior to the establishment of model because their relative abundances were significantly affected by sampling days (age) in $\mathrm{H} 2 \mathrm{H}$ calves (Table $\mathrm{S} 1$ ). The remaining 21 genera whose relative abundance did not change among sampling days were able to differentiate "healthy" and "unhealthy" microbiota with high accuracy $(\mathrm{AUC}=0.713$, Fig. S6a). Based on threefold cross-validation (Fig. S6b), it revealed that 6 of those 21 bacterial genera, including Trueperella, Streptococcus, Dorea, uncultured Lachnospiraceae, Ruminococcus 2, and Erysipelatoclostridium, mostly contributed to the discrimination power of health status with improved performance $(\mathrm{AUC}=0.800$, Fig. S6a). The relative rank of relative abundance of those six microbial markers was plotted against the relative rank of performance represented by AUC (Fig. 4a). Using the profiles of the six bacterial markers as independent variables, the random forest model exhibited an accuracy of 
Fig. 3 Temporal changes of attenuation and buffering values in gut microbiota. a Attenuation value of calves that never exhibited diarrhea $(\mathrm{H} 2 \mathrm{H})$. b Attenuation value of calves that exhibited diarrhea but not treated with Trimidox or Excenel (R2H). c Attenuation value of calves that exhibited diarrhea and treated with Trimidox or Excenel (S2H). d Buffering value of calves that never exhibited diarrhea $(\mathrm{H} 2 \mathrm{H})$. e Buffering value of calves that exhibited diarrhea but not treated with Trimidox or Excenel (R2H). f Buffering value of calves that exhibited diarrhea and treated with Trimidox or Excenel (S2H). Statistical analysis was done by Friedman test and multiple comparisons were performed based on Wilcoxon signed-rank test and subjected to "BH" $P$ value adjustment $(* P \leq 0.05)$.
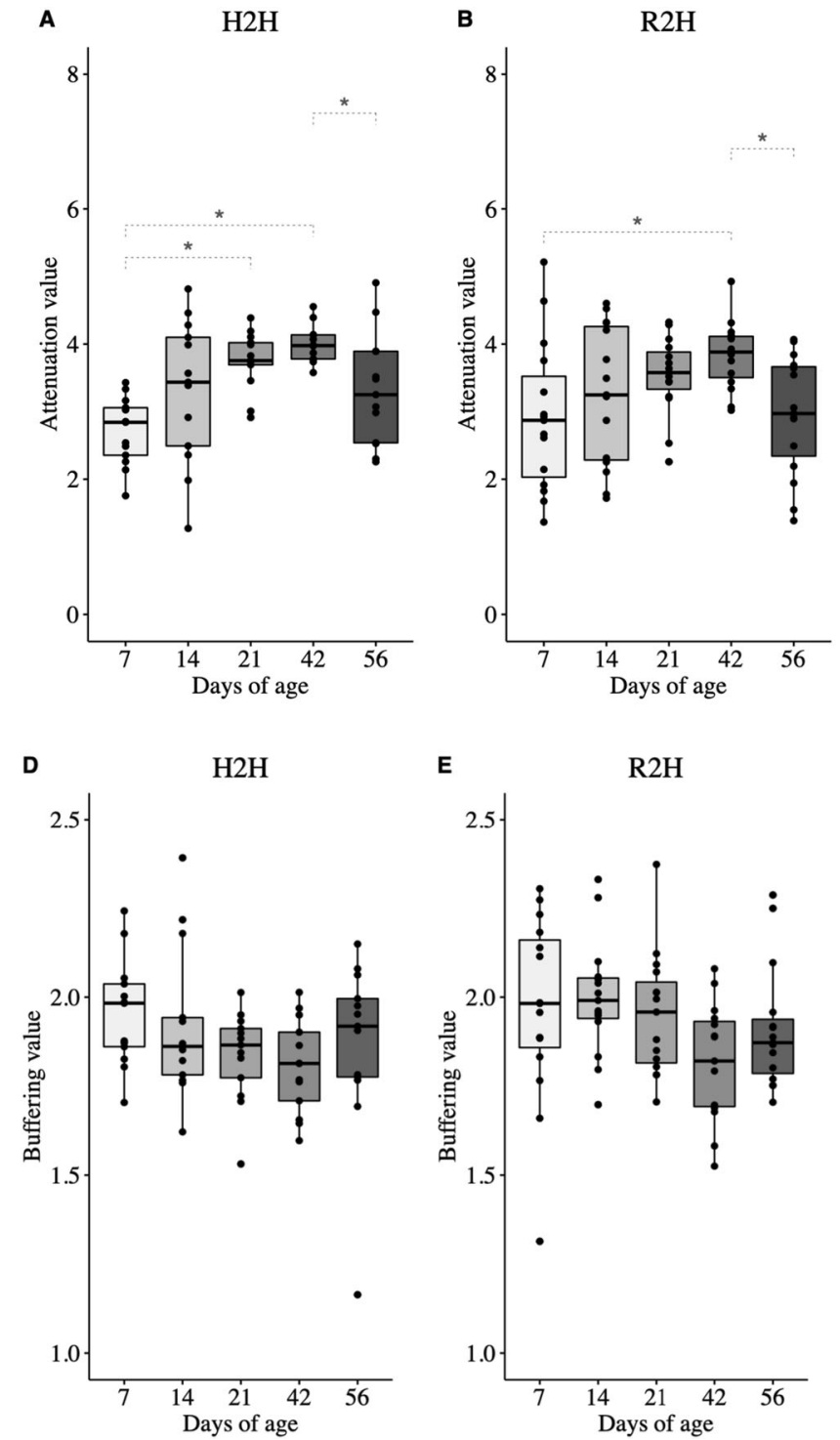

E

R2H

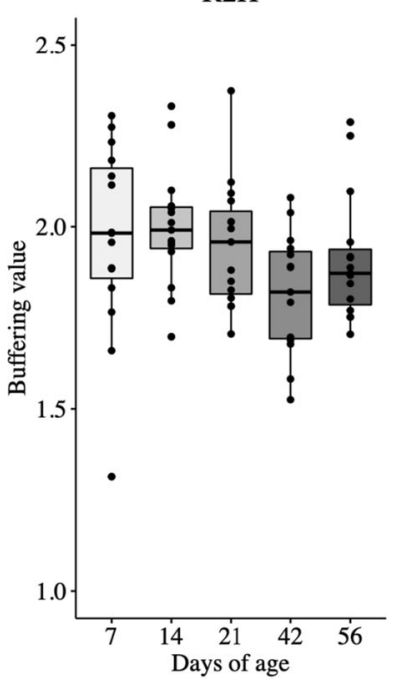

C

S2H

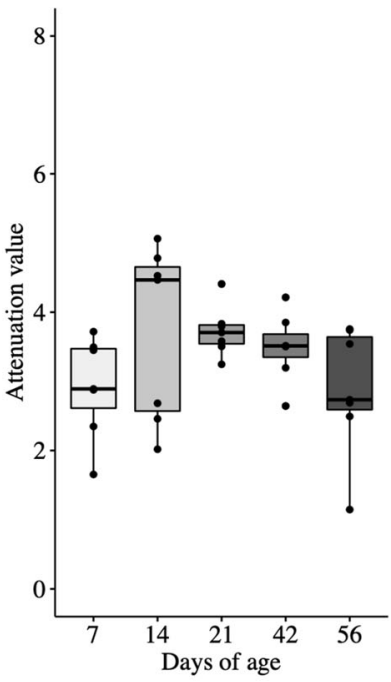

$\mathbf{F}$

S2H

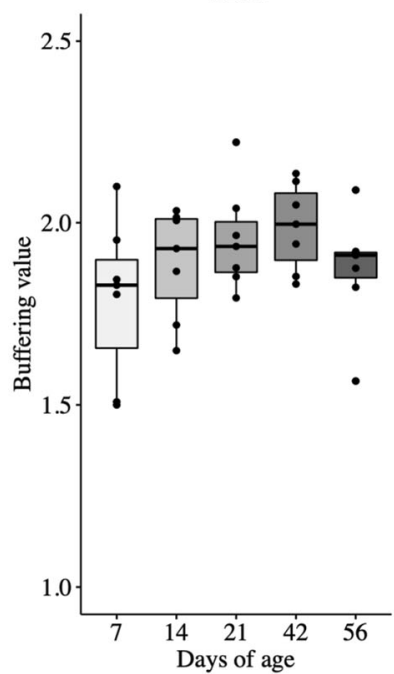

$62.0 \%$ and $84.3 \%$ for predicting "healthy" and "unhealthy" gut microbiota, respectively (Fig. $4 \mathrm{~b}$ ). The relative abundance of uncultured Lachnospiraceae $(P<0.001)$, Ruminococcus $2(P<0.001)$, and Dorea $(P=0.025)$ was higher, and Streptococcus $(P=0.010)$ and Erysipelatoclostridium $(P=0.093)$ tended to be higher in "healthy" microbiota, while that of Trueperella $(P<0.033)$ was higher in "unhealthy" microbiota (Fig. S7).

To further investigate if the difference in the relative abundance of those six microbial markers between "healthy" and "unhealthy" microbiota also existed in their absolute abundance, log-ratio and differential ranking techniques were applied. The log ratio between "unhealthy" and "healthy" microbiota of 178 bacterial genera was ranked by performing multinomial regression (Table S2). The results showed that Trueperella had low ranks (log ratio between "unhealthy" and "healthy" was 1.74 ), while
Erysipelatoclostridium, Ruminococcus 2, Streptococcus, Dorea, and uncultured Lachnospiraceae had high ranks (log ratio between "unhealthy" and "healthy" was -0.07 , $-0.24,-0.36,-0.43$, and -1.43 , respectively) (Fig. 5). The difference in ranks between those taxa revealed that Trueperella was more prevalent in "unhealthy" microbiota, while the other five bacterial genera were more prevalent in "healthy" microbiota relative to other taxa.

\section{Discussion}

Increase in diversity and stability at an early age has been characterized as a feature of establishment of healthy gut microbiota in humans $[35,36]$. In the current study, we observed an increase in Shannon index of gut microbiota from 7 to 56 days of age in both $\mathrm{H} 2 \mathrm{H}$ and R2H calves. Such 

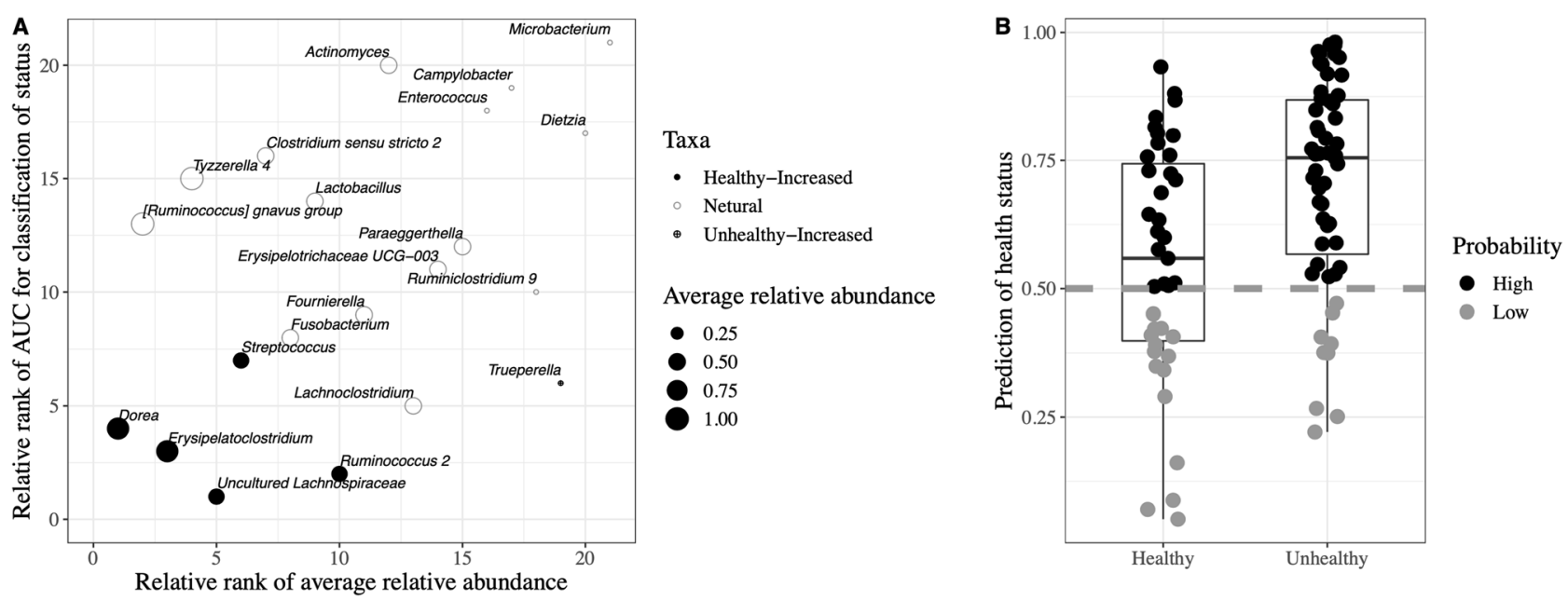

Fig. 4 Prediction of health status based on fecal microbial markers. a The relationship between the contributions of the six most discriminant bacterial genera to classification of microbiota as well as their relative abundance. b Accuracy of the random forest model

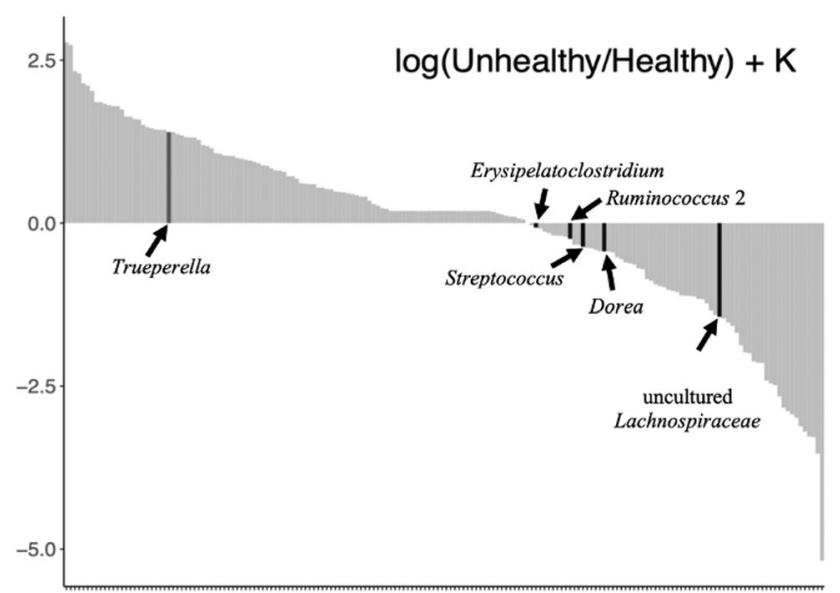

Fig. 5 The ranks of bacterial genera between "healthy" and "unhealthy" gut microbiota estimated using multinomial regression. The $y$-axis represents the log-fold change that is known up to some bias constant $\mathrm{K}$, and the $x$-axis numerically orders the ranks of each genus in the analysis. Truperella is postively associated with 'unhealthy' microbiota while Erysipelatoclostridium, Ruminococcus 2, Streptococcus, Dorea, and uncultured Lachnospiraceae are positively associated with 'healthy' microbiota.

findings are similar to the changes in fecal microbiota in healthy dairy calves during first 8 weeks of age [37, 38]. However, the detected changes in gut microbial diversity in healthy calves of previous studies were largely confounded with diets, as those calves were fed different diets during their experimental trials [37, 38]. To overcome such limitations, the calves in the current study were fed only milk replacer (same amount under the same age), and therefore we speculate that host (age and growth) was the main factor driving the development of microbial diversity in early life of these veal calves. Although the temporal changes in microbial diversity of gut microbiota in $\mathrm{R} 2 \mathrm{H}$ calves was established based on the six most discriminant bacterial genera for discriminating "healthy" $(n=39)$ and "unhealthy" $(n=59)$ microbiota. High indicates a probability above 0.50 , and low indicates a probability below 0.50 .

similar to those in $\mathrm{H} 2 \mathrm{H}$ calves, higher $\mathrm{CV}$ of Shannon index in $\mathrm{R} 2 \mathrm{H}$ than $\mathrm{H} 2 \mathrm{H}$ calves suggests that perturbations due to diarrhea in $\mathrm{R} 2 \mathrm{H}$ calves may cause fluctuation to the development in microbial diversity. The use of therapeutic antimicrobials, on the other hand, "delayed" the temporal development of microbial diversity of gut microbiota from 7 to 21 days of age in $\mathrm{S} 2 \mathrm{H}$ calves, which may be explained by the loss of microorganisms sensitive to antimicrobials as previously reported in human gut microbiota [39]. In addition, the decrease in Bray-Curtis distance between two successive samples reached significant at 42 and 21 days of age, respectively, in $\mathrm{H} 2 \mathrm{H}$ and $\mathrm{R} 2 \mathrm{H}$ groups, but at 56 days of age in $\mathrm{S} 2 \mathrm{H}$ group, suggesting that it may take much longer time for microbiota to become less variable due to the use of antimicrobials. Those findings suggest that therapeutic antimicrobial treatment had more severe negative impact on the temporal development of microbial diversity and stability than diarrhea during the first 21 days of life in veal calves. The insignificant Shannon indices among $\mathrm{R} 2 \mathrm{H}$, $\mathrm{S} 2 \mathrm{H}$, and $\mathrm{H} 2 \mathrm{H}$ calves at 56 days of age may be explained by the relatively long interval after disease/the use of therapeutic antimicrobials, during which the microbial diversity recovered as observed in humans [40, 41]. However, it should be noted that perturbation such as disease and antimicrobial treatment may also lead to an alternative stable but "dysbiosis" microbial community [42]. How those perturbations and altered microbial community affect the health and productivity of calves in their later life deserves further investigation.

To understand how those perturbations affect fecal microbiome (taxonomic and functional composition), we first compared the bacterial composition among $\mathrm{H} 2 \mathrm{H}, \mathrm{R} 2 \mathrm{H}$, and $\mathrm{S} 2 \mathrm{H}$ calves. As most of the diarrhea incidence occurred 
in veal calves between 7 and 21 days of age, we speculated that the lower relative abundance of Blautia and higher relative abundance of Escherichia-Shigella at 14 days of age in $\mathrm{R} 2 \mathrm{H}$ than $\mathrm{H} 2 \mathrm{H}$ calves may be associated with diarrhea. High prevalence of Blautia has been reported in colon and fecal microbiota of healthy neonatal swine [43] and human infants $[44,45]$. On the contrary, the reduction in the abundance of this genus was reported in fecal samples of dogs with diarrhea [46] and enteropathy [47]. Blautia utilizes polysaccharides that other gut microorganisms cannot degrade [48] and produces butyrate, one of the major SCFA that maintains gut health via regulation of the immune system [49] and/or maintenance of the intestinal epithelial barrier [50]. On the other hand, many species of Escherichia-Shigella, e.g. E. coli [51] and S. flexneri [52], are widely accepted as the major pathogens to cause bovine diarrhea. Although there was no difference in the relative abundance of any bacterial genus at any age between $\mathrm{H} 2 \mathrm{H}$ and $\mathrm{S} 2 \mathrm{H}$ calves, the detected higher relative abundance of predicted genes involved in antimicrobial resistance in $\mathrm{S} 2 \mathrm{H}$ compared with $\mathrm{H} 2 \mathrm{H}$ calves suggests that the changes of microbiota in response to the antimicrobials may occur not necessarily at compositional level but at functional level [53]. It has been reported that short-term antimicrobial treatment drove the gut microbiota to a more resilient state to future antimicrobial treatment in adult human due to the persistence of these increased antimicrobial-resistant genes for years [40]. In this regard, higher relative abundance of predicted microbial genes associated with antimicrobial resistance (bla regulator protein blaRl, penicillin-binding protein 1 and 3, aureolysin) at 56 days of age in H2S calves may potentially increase the risk of failure of future antimicrobial treatment.

Changes in the abundance of members could result in a minor or major alteration to a community's functional profile, depending on the stability of microbiota [54]. Stability relates to the concept that stable equilibrium status exists for a microbial community, in which disturbances and temporal dynamics of individual members cause changes, but the community as a whole has the ability to restore such changes to the original status [55]. A community with higher stability is more resilient to external perturbations so its functional profile is less likely to change. Based on the attenuation and buffering values of three group of calves, higher attenuation implies that smaller functional shifts are expected in a community given similar levels of perturbation, while higher buffering indicates that larger perturbations are needed before a significant functional shift could be observed [28]. No temporal change in buffering was observed in either group, indicating that similar level of perturbations is required to cause a substantial functional shift regardless of sampling time, disease, or antimicrobial treatment. However, our results suggest that in $\mathrm{H} 2 \mathrm{H}$ calves, the temporal development of stability was featured by a significant increase in attenuation value from 7 to 21 days of age, a pattern that was not observed in $\mathrm{R} 2 \mathrm{H}$ or $\mathrm{S} 2 \mathrm{H}$ calves. Higher attenuation in $\mathrm{H} 2 \mathrm{H}$ calves may ensure the maintenance of functional capacities of the fecal microbial community in the face of ecological dysbiosis during early life. In comparison, the increase in attenuation value in $\mathrm{R} 2 \mathrm{H}$ calves may be "delayed," as it was not different between 21 and 7 days of age. The potential delay in the increase of attenuation over time in $\mathrm{R} 2 \mathrm{H}$ calves may reflect gradual recovery of temporal stability after disease (diarrhea). Although we expected similar delay of the increase in attenuation in $\mathrm{S} 2 \mathrm{H}$ as in $\mathrm{R} 2 \mathrm{H}$ calves, the increase in attenuation was not observed in $\mathrm{S} 2 \mathrm{H}$ calves. As it was reported that antimicrobial treatment may disrupt microbial community function [25], our results suggest that antimicrobial treatment may have a more negative impact on the temporal development of stability of gut microbiota compared with disease (such as diarrhea). Future studies using shotgun metagenomics may be able to determine the factors driving microbial resilience during early life, which is crucial for designing strategies to minimize the negative impact of antimicrobial treatment on microbial stability of veal calves. Despite those findings, it should be noted that further increase in sample size may be needed to validate those differences, as early life gut microbiota is featured by high between-individual variabilities indicated by the high SEM of relative abundance of bacterial genera (Table S1).

Considering the negative effect of perturbation due to diarrhea/antimicrobial treatment on temporal development of microbial diversity and stability, early prediction of diarrhea based on microbial markers may be a promising method to avoid such perturbations. Our results revealed higher prevalence of butyrate-producing bacteria belonging to families Lachnospiraceae (uncultured Lachnospiraceae and Dorea) and Ruminococcaceae (Ruminococcus 2) in healthy calves. Those bacterial genera were also reported in "healthy" microbiota in human beings or animals. Specifically, the relative abundance of $R$. bromii was higher [56], while that of Dorea was lower [57] in gut microbiota of healthy human subjects compared with Crohn's disease patients. In addition, Erysipelatoclostridium was reported to be highly abundant in the hindgut digesta of healthy calves at 7 days of age [58]. Streptococcus, which was also enriched in "healthy" microbiota, contains strains such as $S$. infantarius and $S$. equines in bovine fecal samples, exhibited anti-Salmonella activities [59]. Our results highlight the potential of using these butyrate-producing bacteria as microbial markers for identifying healthy (high prevalence) or unhealthy (low prevalence) in young ruminants. On the contrary, Trueperella was reported as an opportunistic pathogen that may cause diverse pyogenic infections such as liver abscessation [60] and gastroenteritis [61] in cattle. 
Although the function of Trueperella has not been well studied in the gastrointestinal tract of calves, it can be speculated that this bacterial genus may potentially cause infections to in the gastrointestinal tract of calves and therefore be associated with the prevalence of diarrhea. Future studies are needed to investigate the mechanism of action of those microbial markers on the modulation of gut health in young ruminants.

The development of sequencing techniques and modeling algorithms facilitates the application of microbiota to predict the risk of disease outbreaks, which is one of the goals of microbiome research [12]. However, studies are still limited, and to our knowledge no study has been conducted in the prediction of disease onset based on gut microbiota in young ruminants. Teng et al. [16] exploited microbial indicators of dental caries (Prevotella spp.) after excluding the age-discriminatory taxa, yielding a predicting accuracy of $81 \%$. More recently, it is reported that disease initiation can be diagnosed using gut microbial indicators with $95 \%$ accuracy in shrimp [62]. In this study, we initially tried to establish the model based on 72 samples from CON calves (39 healthy and 33 unhealthy) only. However, the prediction accuracy for "unhealthy" microbiota was $<70 \%$ (data not shown). After including the 26 samples from SCB calves in the model, the prediction accuracy of "unhealthy" microbiota reached $84.3 \%$, suggesting that early life microbiota has the potential to be employed for disease (such as diarrhea) prediction in young ruminants. It should be noted that in spite of the prediction model established by us and others, it is still challenging to predict human and animal diseases using microbial markers in practice. One of the reasons may be due to the fact that the "relative abundance" of microbial markers was used in those model establishing studies, which is difficult to compare among studies and make reproducible analyses due to the constraints of compositional data [63]. Recently, a novel method, differential abundance analysis, may address the issue of misinterpretation of compositional data and provide insight into the absolute change in microbiota between two conditions, as the ranks of relative differentials are identical to the ranks of absolute differentials [33]. By applying this method, it is suggested that Trueperella was positively associated with "unhealthy" microbiota, while the other five bacterial genera were positively associated with "healthy" microbiota. This further highlighted that the difference in the relative abundance of those six markers correctly reflects their absolute difference between "healthy" and "unhealthy" microbiota. One of the limitations of our study is that for most of diarrheic calves, only one sampling time (7 days of age) was available prior to incidence of diarrhea, which may not be sufficient to reflect the changes in gut microbiota during disease processes. Therefore, studies are needed to verify if and how those microbial markers play a role in the process of diarrhea in newborn calves with more sampling time points and different populations to determine their prediction specificity of diarrhea in young ruminants. It is also important to be noted that it may not be easy to choose a "optimal" or even "suitable" external cohort for validation of the random forest model for the current study. Due to the heterogeneity of DNA extraction, library preparation, sequencing, and bioinformatic techniques, metaanalyses among studies [64], the standardized microbial analysis pipeline should be developed in order to test the robustness of microbial classifiers developed based on machine learning algorithm such as the random forest model among studies.

\section{Conclusion}

Increased microbial diversity and stability are important features of temporal development of gut microbiota in healthy calves. However, the use of therapeutic antimicrobials for treating diarrhea resulted in delayed temporal development of diversity and stability of early life gut microbiota especially during 7 to 21 days of age, as well as increased relative abundance of predicted genes related to antimicrobial resistance at 56 days of age, suggesting that therapeutic antimicrobials may have negative impact on the long-term health of calves. Future studies of the relationship between changes in microbial composition/function in response to antimicrobials and gut health and productivity of calves is warranted using functional analysis such as metagenomics and/or culturomics to elucidate the mode of action of bacterial markers on the modulation of gut health of young ruminants. Using the random forest model, this study showed a promise to predict diarrhea in calves using gut microbiota. However, samples with unknown health status should be used to assess the accuracy of the current model as well as validation in different populations and animal herds in the future. Regardless, our study highlights the possibility of employing early life microbiota for predicting other types of disease or infections in neonatal foodproducing animals.

Acknowledgements This work was funded by the Natural Sciences and Engineering Research Council of Canada (NSERC), Lallemand Animal Nutrition, Grober Animal Nutrition, Westgen, BC Dairy Association, Alberta Milk, Sask-Milk, and Dairy Farmers of Manitoba and by the Agricultural Science and Technology Innovation Program of the Chinese Academy of Agricultural Sciences and Chinese Scholarship Council Scholarship. We appreciate technical support and guidance from Drs A. Eng and E. Borenstein (University of Washington), F. Chaucheyras-Durand, M. Castex, and A. Aguilar (Lallemand Animal Nutrition), and A. Kerr and H. Copland (Grober Animal Nutrition). 


\section{Compliance with ethical standards}

Conflict of interest The authors declare that they have no conflict of interest.

Publisher's note Springer Nature remains neutral with regard to jurisdictional claims in published maps and institutional affiliations.

\section{References}

1. Mathew AG, Cissell R, Liamthong S. Antibiotic resistance in bacteria associated with food animals: a United States perspective of livestock production. Foodborne Pathog Dis. 2007;4:115-33.

2. Bauer E, Williams BA, Smidt H, Verstegen MW, Mosenthin R. Influence of the gastrointestinal microbiota on development of the immune system in young animals. Curr Issues Intest Microbiol. 2006;7:35-52.

3. Hulbert LE, Moisá SJ. Stress, immunity, and the management of calves. J Dairy Sci. 2016;99:3199-216.

4. Gensollen T, Iyer SS, Kasper DL, Blumberg RS. How colonization by microbiota in early life shapes the immune system. Science. 2016;352:539-44.

5. Kerr CA, Grice DM, Tran CD, Bauer DC, Li D, Hendry P, et al. Early life events influence whole-of-life metabolic health via gut microflora and gut permeability. Crit Rev Microbiol. 2015;41:326-40.

6. Zeissig S, Blumberg RS. Life at the beginning: perturbation of the microbiota by antibiotics in early life and its role in health and disease. Nat Immunol. 2014;5:307-10.

7. Cox LM, Blaser MJ. Antibiotics in early life and obesity. Nat Rev Endocrinol. 2015;11:182-90.

8. Oikonomou G, Teixeira AG, Foditsch C, Bicalho ML, Machado VS, Bicalho RC. Fecal microbial diversity in pre-weaned dairy calves as described by pyrosequencing of metagenomic $16 \mathrm{~S}$ rDNA. Associations of Faecalibacterium species with health and growth. PloS ONE. 2013;8:e63157.

9. Oultram J, Phipps E, Teixeira AG, Foditsch C, Bicalho ML, Machado VS, et al. Effects of antibiotics (oxytetracycline, florfenicol or tulathromycin) on neonatal calves' faecal microbial diversity. Vet Rec. 2015;177:598.

10. Beisner BE, Haydon DT, Cuddington K. Alternative stable states in ecology. Front Ecol Environ. 2003;1:376-82.

11. McEachran AD, Blackwell BR, Hanson JD, Wooten KJ, Mayer GD, Cox SB, et al. Antibiotics, bacteria, and antibiotic resistance genes: aerial transport from cattle feed yards via particulate matter. Environ Health Persp. 2015;123:337-43.

12. Cho Y, Yoon K-J. An overview of calf diarrhea-infectious etiology, diagnosis, and intervention. J Vet Sci. 2014;15:1-17.

13. Knights D, Parfrey LW, Zaneveld J, Lozupone C, Knight R. Human-associated microbial signatures: examining their predictive value. Cell Host Microbe. 2011;10:292-6.

14. Qin J, Li Y, Cai Z, Li S, Zhu J, Zhang F, et al. A metagenomewide association study of gut microbiota in type 2 diabetes. Nature. 2012;490:55-60.

15. Le Chatelier E, Nielsen T, Qin J, Prifti E, Hildebrand F, Falony G, et al. Richness of human gut microbiome correlates with metabolic markers. Nature. 2013;500:541-6.

16. Teng F, Yang F, Huang S, Bo C, Xu ZZ, Amir A, et al. Prediction of early childhood caries via spatial-temporal variations of oral microbiota. Cell Host Microbe. 2015;18:296-306.

17. Villot C, Ma T, Renaud D, Hosseini-Ghaffari M, Gibson DJ, Skidmore A, et al. Saccharomyces cerevisiae boulardii CNCM I1079 affects health, growth and fecal microbiota in milk-fed veal calves. J Dairy Sci. 2019;102:7011-25.
18. Lesmeister K, Heinrichs A. Effects of corn processing on growth characteristics, rumen development, and rumen parameters in neonatal dairy calves. J Dairy Sci. 2004;87:3439-50.

19. Buts JP, De Keyser N. Effects of Saccharomyces boulardii on intestinal mucosa. Dig Dis Sci. 2006;51:1485-92.

20. $\mathrm{Yu} \mathrm{Z}$, Morrison M. Comparisons of different hypervariable regions of $r r s$ genes for use in fingerprinting of microbial communities by PCR-denaturing gradient gel electrophoresis. Appl Environ Micro. 2004;70:4800-6.

21. Kroes I, Lepp PW, Relman DA. Bacterial diversity within the human subgingival crevice. Proc Natl Acad Sci USA. 1999;96:14547-52.

22. Bolyen E, Rideout JR, Dillon MR, Bokulich NA, Abnet CC, AlGhalith GA, et al. Reproducible, interactive, scalable and extensible microbiome data science using QIIME2. Nat Biotechnol. 2019;37:852-7.

23. Callahan BJ, McMurdie PJ, Rosen MJ, Han AW, Johnson AJA, Holmes SP. DADA2: high-resolution sample inference from Illumina amplicon data. Nat Methods. 2016;13:581-3.

24. Davis NM, Proctor DM, Holmes SP, Relman DA, Callahan BJ. Simple statistical identification and removal of contaminant sequences in marker-gene and metagenomics data. Microbiome. 2018;6:226.

25. Heberle H, Meirelles GV, da Silva FR, Telles GP, Minghim R. InteractiVenn: a web-based tool for the analysis of sets through Venn diagrams. BMC Bioinform. 2015;16:169.

26. Douglas GM, Maffei VJ, Zaneveld J, Yurgel SN, Brown JR, Taylor CM, et al. PICRUSt2: an improved and extensible approach for metagenome inference. BioRxiv. 2019:672295.

27. Bokulich NA, Dillon MR, Zhang Y, Rideout JR, Bolyen E, Li H, et al. q2-longitudinal: longitudinal and paired-sample analyses of microbiome data. mSystems. 2018;3:e0219-18.

28. Eng A, Borenstein E. Taxa-function robustness in microbial communities. Microbiome. 2018;6:45.

29. Urie NJ, Lombard JE, Shivley CB, Kopral CA, Adams AE, Earleywine TJ, et al. Preweaned heifer management on US dairy operations: part V. Factors associated with morbidity and mortality in preweaned dairy heifer calves. J Dairy Sci. 2018;101:9229-44.

30. Cawley GC, Talbot NL. On over-fitting in model selection and subsequent selection bias in performance evaluation. J Mach Learn Res. 2010;11:2079-107.

31. Vandeputte D, Kathagen G, D'hoe K, Vieira-Silva S, VallesColomer M, Sabino J, et al. Quantitative microbiome profiling links gut community variation to microbial load. Nature. 2017;551:507-11

32. Abadi M, Barham P, Chen J, Chen Z, Davis A, Dean J, et al. Tensorflow: a system for large-scale machine learning. In: 12th USENIX symposium on operating systems design and implementation (OSDI 16); USENIX Association, Savannah, GA, 2016. p. $265-83$.

33. Morton JT, Marotz C, Washburne A, JSilverman J, Zaramela LS, Edlund A, et al. Establishing microbial composition measurement standards with reference frames. Nat Commun. 2019;10:2719.

34. Benjamini Y, Hochberg Y. Controlling the false discovery rate: a practical and powerful approach to multiple testing. J R Stat Soc B. 1995;57:289-300.

35. Yatsunenko T, Rey FE, Manary MJ, Trehan I, Dominguez-Bello MG, Contreras M, et al. Human gut microbiome viewed across age and geography. Nature. 2012;486:222-7.

36. Palmer C, Bik EM, DiGiulio DB, Relman DA, Brown PO. Development of the human infant intestinal microbiota. PLoS Biol. 2007;5:e177.

37. Klein-Jöbstl D, Schornsteiner E, Mann E, Wagner M, Drillich M, Schmitz-Esser S. Pyrosequencing reveals diverse fecal microbiota 
in Simmental calves during early development. Front Microbiol. 2014;5:622.

38. Dill-McFarland KA, Breaker JD, Suen G. Microbial succession in the gastrointestinal tract of dairy cows from 2 weeks to first lactation. Sci Rep. 2017;7:40864.

39. Panda S, El khader I, Casellas F, Vivancos JL, Cors MG, Santiago A, et al. Short-term effect of antibiotics on human gut microbiota. PLoS ONE. 2014;9:e95476.

40. Jakobsson HE, Jernberg C, Andersson AF, Sjölund-Karlsson M, Jansson JK, Engstrand L. Short-term antibiotic treatment has differing long-term impacts on the human throat and gut microbiome. PloS ONE. 2010;5:e9836.

41. Pérez-Cobas AE, Gosalbes MJ, Friedrichs A, Knecht H, Artacho A, Eismann K, et al. Gut microbiota disturbance during antibiotic therapy: a multi-omic approach. Gut. 2013;62:1591-601.

42. Sommer F, Anderson JM, Bharti R, Raes J, Rosenstiel P. The resilience of the intestinal microbiota influences health and disease. Nat Rev Microbiol. 2017;15:630-8.

43. Saraf MK, Piccolo BD, Bowlin AK, Mercer KE, LeRoith T, Chintapalli SV, et al. Formula diet driven microbiota shifts tryptophan metabolism from serotonin to tryptamine in neonatal porcine colon. Microbiome. 2017;5:77.

44. Jost T, Lacroix C, Braegger CP, Rochat F, Chassard C. Vertical mother-neonate transfer of maternal gut bacteria via breastfeeding. Environ Microbiol. 2013;16:2891-904.

45. Sagheddu V, Patrone V, Miragoli F, Morelli L. Abundance and diversity of hydrogenotrophic microorganisms in the infant gut before the weaning period assessed by denaturing gradient gel electrophoresis and quantitative PCR. Front Nutr. 2017;4:29.

46. Minamoto Y, Dhanani N, Markel ME, Steiner JM, Suchodolski JS. Prevalence of Clostridium perfringens, Clostridium perfringens enterotoxin and dysbiosis in fecal samples of dogs with diarrhea. Vet Microbiol. 2014;174:463-73.

47. AlShawaqfeh MK, Wajid B, Minamoto Y, Markel M, Lidbury JA, Steiner JM, et al. A dysbiosis index to assess microbial changes in fecal samples of dogs with chronic inflammatory enteropathy. FEMS Microbiol Ecol. 2017;93:fix136.

48. Flint HJ, Bayer EA, Rincon MT, Lamed R, White BA. Polysaccharide utilization by gut bacteria: potential for new insights from genomic analysis. Nat Rev Microbiol. 2008;6:121-31.

49. Furusawa Y, Obata Y, Fukuda S, Endo TA, Nakato G, Takahashi $\mathrm{D}$, et al. Commensal microbe-derived butyrate induces the differentiation of colonic regulatory $\mathrm{T}$ cells. Nature. 2013;504:446-50.

50. Ruemmele FM, Schwartz S, Seidman EG, Dionne S, Levy E, Lentze MJ. Butyrate induced Caco-2 cell apoptosis is mediated via the mitochondrial pathway. Gut. 2003;52:94-100.
51. Bartels CJM, Holzhauer M, Jorritsma R, Swart WAJM, Lam TJGM. Prevalence, prediction and risk factors of enteropathogens in normal and non-normal faeces of young Dutch dairy calves. Prev Vet Med. 2010;93:162-9.

52. Zhu Z, Cao M, Zhou X, Li B, Zhang J. Epidemic characterization and molecular genotyping of Shigella flexneri isolated from calves with diarrhea in Northwest China. Antimicrob Resist Infect Control. 2017;6:92.

53. Ma X, Zhang Q, Zheng M, Gao Y, Yuan T, Hale L, et al. Microbial functional traits are sensitive indicators of mild disturbance by lamb grazing. ISME J. 2019;13:1370-3.

54. Moya A, Ferrer M. Functional redundancy-induced stability of gut microbiota subjected to disturbance. Trends Microbiol. 2016;24:402-13.

55. Lozupone CA, Stombaugh JI, Gordon JI, Jansson JK, Knight R. Diversity, stability and resilience of the human gut microbiota. Nature. 2012;13:220-30.

56. Mondot S, Kang S, Furet JP, de Cárcer AD, McSweeney C, Morrison M, et al. Highlighting new phylogenetic specificities of Crohn's disease microbiota. Inflamm Bowel Dis. 2011;17:185-92.

57. Sokol H, Jegou S, McQuitty C, Straub M, Leducq V, Landman C, et al. Specificities of the intestinal microbiota in patients with inflammatory bowel disease and Clostridium difficile infection. Gut Microbes. 2018;9:55-60.

58. Song Y, Malmuthuge N, Steele MA, Guan LL. Shift of hindgut microbiota and microbial short chain fatty acids profiles in dairy calves from birth to pre-weaning. FEMS Microbiol Ecol. 2018;93: fix 179 .

59. Adetoye A, Pinloche E, Adeniyi BA, Ayeni FA. Characterization and anti-salmonella activities of lactic acid bacteria isolated from cattle faeces. BMC Microbiol. 2018;18:96.

60. Rzewuska M, Kwiecień E, Chrobak-Chmiel D, Kizerwetter-Świda M, Stefańska I, Gieryńska M. Pathogenicity and virulence of Trueperella pyogenes: a review. Int J Mol Sci. 2019;20:2737.

61. Hurst CJ. Opportunistic bacteria associated with mammalian livestock disease. In: The connections between ecology and infectious disease. Cham: Springer; 2018. p. 185-238.

62. Xiong J, Zhu J, Dai W, Dong C, Qiu Q, Li C. Integrating gut microbiota immaturity and disease-discriminatory taxa to diagnose the initiation and severity of shrimp disease. Environ Microbiol. 2017;19:1490-501.

63. Gloor GB, Wu JR, Pawlowsky-Glahn V, Egozcue JJ. It's all relative: analyzing microbiome data as compositions. Ann Epidemiol. 2016;26:322-9.

64. Langille MG. Exploring linkages between taxonomic and functional profiles of the human microbiome. MSystems. 2018;3: e00163-17. 